\section{El laberinto}

del fauno y

La forma

del agua:

la representación femenina $y$ el amor en el cine de Guillermo del Toro

Pan's Labyrinth and The Shape of Water:

Feminine representation and love in the cinema of

Guillermo del Toro

SALVAdor IVÁN

Lupercio Madero

salvador.luperciom@alumnos.udg.mx

Universidad de Guadalajara, México.

FECHA DE RECEPCIÓN febrero 11, 2019

FECHA DE APROBACIÓN septiembre 25, 2019

FECHA dE PUBLICACIÓN enero 1, 2020

https://doi.org/10.32870/ elojoquepiensa.v0i20.302
RESUMEN / Una constante en la filmografía de Guillermo del Toro es la figura femenina como protagonista, en quienes la emoción del amor funge como revulsivo de la trama. Estos dos elementos, la feminidad y el amor, serán los hilos conductores en este trabajo, el cual se enfoca en dos filmes: El laberinto del fauno (2006) y La forma del agua (2017). Este texto se centra en el análisis de la representación de la mujer en estas dos películas, vinculándola al concepto del amor, con la hipótesis de que en ambas se representa una feminidad moderna, siendo el amor el que produce una reafirmación de esta.

Palabras Clave / amor, feminidad, relaciones de pareja, Guillermo del Toro.
Abstract / A constant in Guillermo del Toro's filmography is the female figure as the protagonist, in whom the emotion of love serves as a plot revulsion. These two elements, femininity and love, will be the unifying thread in this work, which focuses on two films: Pan's Labyrinth (2006) and The Shape of Water (2017). This text focuses on the analysis of the representation of women in these two films, linking it to the concept of love, with the hypothesis that in both a modern femininity is represented, being love the one that produces a reaffirmation of this.

KeYWORDS / love, femininity, relationships, Guillermo del Toro. 

(The Shape of Water, 2017) del director Guillermo del Toro (Guadalajara, 1964- ) tuvieron una gran recepción tanto de la crítica como tagonistas de ambas películas representan una concepción moderna de lo femenino, alejada de lo tradicional, y cómo el amor aparece como un revulsivo en el desenlace de sus argumentos.

Si bien esta afirmación es arriesgada en sí, aquí la modernidad se entiende como los aspectos que se van modificando (por ejemplo, los roles de género, las relaciones de pareja, o la sexualidad, por mencionar algunos) en el contexto convulso en que se sitúa la trama creada por Del Toro. Siguiendo a Echeverría (2009), la modernidad se podría entender como:

${ }^{1}$ La película El laberinto del fauno tuvo una recaudación mundial de 87041569 dólares; por su parte, La forma del agua recaudó 194349972 dólares. 
La característica determinante de un conjunto de comportamientos que aparecen desde hace ya varios siglos por todas partes en la vida social y que el entendimiento común reconoce como discontinuos e incluso contrapuestos -esa es su percepción- a la constitución tradicional de esa vida, comportamientos a los que precisamente llama "modernos". Se trata además de un conjunto de comportamientos que estaría en proceso de sustituir esa constitución tradicional, después de ponerla en evidencia como obsoleta, es decir, como inconsistente e ineficaz (pp. 7-8).

Por su lado, Anthony Giddens (1995a) considera que en la modernidad se da una configuración de la personalidad, desligada de los aspectos tradicionales de la sociedad, en donde existe una definición particular del yo, una nueva visión del uso del cuerpo y otras maneras de elección sobre los diferentes aspectos que engloban la vida personal, de pareja, familiar, lo que evidentemente trae cambios considerables referente a la perspectiva a la que anteriormente se les asociaba a estas esferas.

Considero relevante señalar el empeño que Guillermo del Toro pone a estos aspectos mencionados por el contraste con otros filmes apegados a la tradición estadounidense, donde en el discurso está internalizada una representación tradicional de la mujer, aunque a primera vista pudiera aparentar lo contrario ${ }^{2}$.

Este análisis se realiza en parte desde un enfoque interpretativo, tomando en consideración el contexto histórico de las épocas en que se desarrollan las ficciones de estas dos películas, dando por sentado el trabajo de Del Toro como guionista y articulador de sus discursos. Aunque en este escrito no se busca realizar un análisis simbólico propiamente, sí echa mano de elementos iconográficos que se encuentren en los filmes, con el fin de entablar un dialogo, en medida de lo

\footnotetext{
${ }^{2}$ Véase "La sexualidad femenina en el discurso de la prensa popular y la ficción televisiva", de Rodríguez Salazar y Pérez Sánchez (2014); "Ideales y anti-ideales de sexualidad femenina en escenas de consejería sexual en una serie de ficción televisiva”, de Rodríguez Salazar y Rodríguez Morales (2016); y "50 sombras de Grey como metáfora de los dilemas afectivos y sexuales contemporáneos”, de Rodríguez Morales (2016).
}

posible, entre el director y algunos autores que han analizado algún aspecto particular en estas cintas.

\section{El LABERINTO deL fauno}

Este filme se centra en Ofelia, una niña de 13 años con interés en la literatura fantástica, quien se ve obligada a pasar la mayoría del tiempo sola, ya que su madre, Carmen, al estar postrada en una cama tiene que relegar su cuidado a Mercedes, la ama de llaves que se encuentra encargada del servicio de la pequeña aldea militar franquista, El Molino. Este lugar al norte de España ha sido comisionado al padrastro de Ofelia, el capitán Vidal. El filme inicia cuando Vidal manda traer a su esposa embarazada y a su hijastra a la aldea porque considera que "un hijo debe nacer dondequiera que esté su padre”, frase que desde el inicio y con el tono en que es proclamada por el capitán, nos da un vistazo de su personalidad, así como del entorno patriarcal que le rodea.

El laberinto del fauno se sitúa en el marco de la posguerra civil española, en el año 1944. En ese momento se da, entre tantos otros, un cambio social respecto al desempeño de la mujer en trabajos especializados, que antes eran exclusivamente llevados a cabo por hombres, a consecuencia de la segunda guerra mundial. Pese que al finalizar la guerra el hombre regresó al trabajo y existió un cierto retroceso en los espacios ganados por las mujeres, la mentalidad de ellas había sido modificada y se reflejará en los posteriores movimientos sociales $^{3}$.

Aunque a lo largo de la historia se pueden encontrar vestigios de posicionamientos feministas (Guillermine de

${ }^{3}$ Jane S. Jaquette (1996) señala cómo a partir de la segunda guerra mundial las condiciones de vida urbana originaron redes de organización en los barrios, quienes presionaban para obtener y mejorar los servicios urbanos, y en ese contexto las mujeres tuvieren un papel sumamente activo. Por otro lado, Susana Gamba (2008) destaca las aportaciones de lo que llama "el feminismo como movimiento social" (o Nuevo Feminismo), de autoras como Simone de Beauvoir y Betty Friedan, cuyas obras repercuten en los movimientos feministas de fines de los 60 en Estados Unidos y Europa, en donde se plantea la redefinición de conceptos como patriarcado, trabajo doméstico, sexualidad, entre otros. 


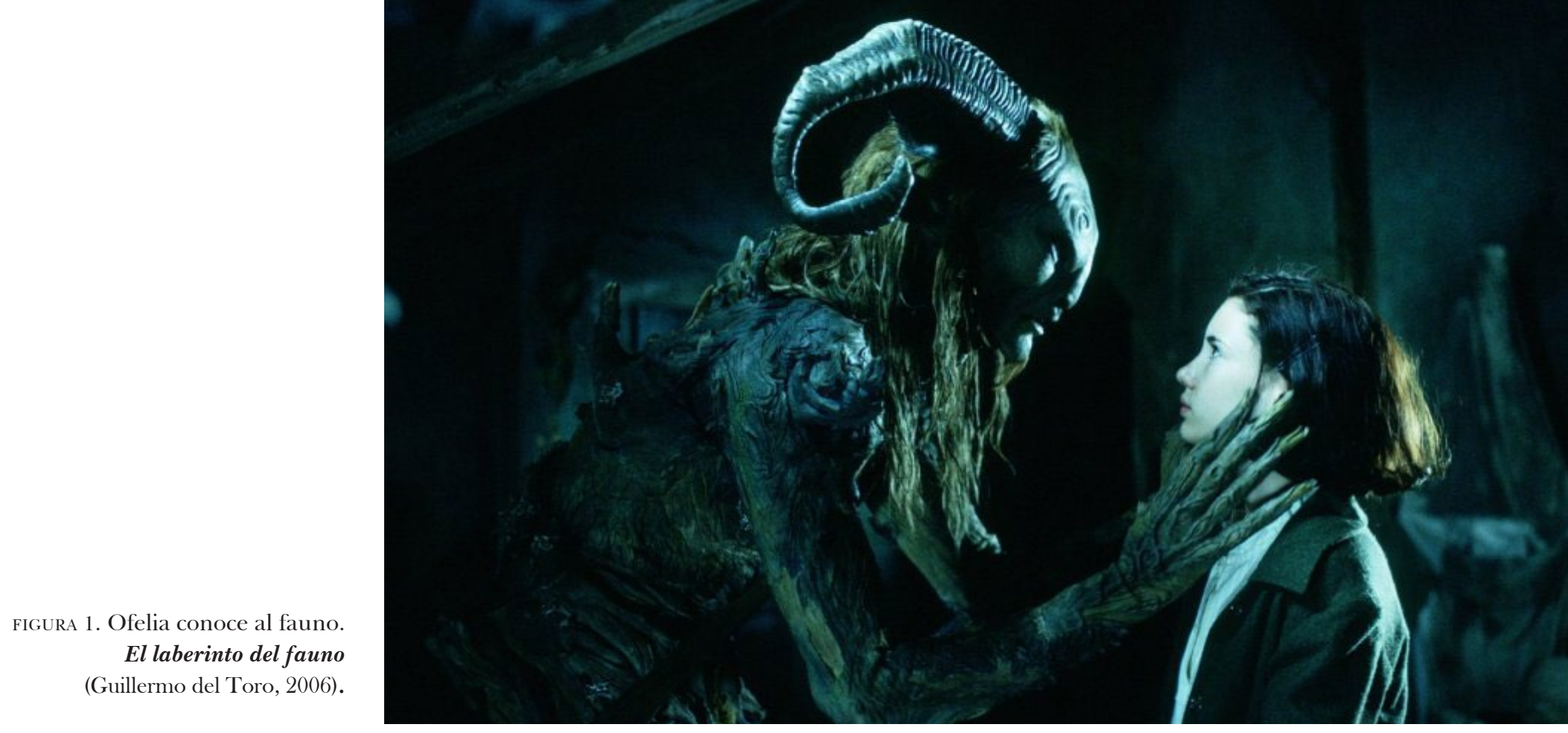

Bohemia, Christine de Pizan, las suffragettes, entre otras), el que se deriva de este periodo de guerra es destacable por la cantidad de mujeres que súbitamente cambiaron su modo de vida en un lapso de tiempo relativamente breve ${ }^{4}$. Es precisamente en este momento convulso, cuando las mujeres están en un proceso de una radical modificación de su identidad, en donde el director y guionista mexicano sitúa su relato.

Una noche, guiada por un hada, Ofelia es conducida por un laberinto, una construcción antigua al lado de El Molino, en donde conoce a un fauno ${ }^{5}$, quien le revela que ella es una princesa y que su padre la espera en su reino, pero para poder llegar a él necesita pasar por tres pruebas que evidencien su linaje [FigURA 1]. Entre tanto, en el mundo de la realidad, la aldea franquista se encuentra rodeada por rebeldes republicanos en las montañas, los Rojos. Estos cuentan con infiltrados en El Molino, entre los que se incluyen Mercedes, la ama de llaves, y el doctor Ferreiro, quien da tratamiento a la endeble esposa embarazada del capitán Vidal y aprovecha su posición

\footnotetext{
${ }^{4}$ Para autoras como Federici (en Gago, abril de 2015) el impacto que tuvo la segunda guerra mundial en las mujeres las llevó a tener cierto desafecto por la reproducción sexual, hizo entender a las mujeres que debían independizarse y rechazar la dependencia hacia los hombres y la familia patriarcal.

${ }^{5} \mathrm{El}$ fauno es un ser mitológico de la tradición romana. Del Toro se basa plenamente en las características con las que se le representa regularmente: un ser hibrido, con características humanas de la cintura hacia arriba, y de cabra de la cintura hacia abajo, entremezclándose ambas en sus facciones.
}

de confianza para robar medicamentos para la resistencia. El filme de Del Toro alterna entre los acontecimientos de la aldea y el mundo onírico de Ofelia, en donde lo que acontece en uno, repercute en el otro.

Las tres pruebas:

la superación de la representación tradicional de la feminidad

Como otras películas de Del Toro, el filme inicia con una voz en off que nos da la sensación de estar leyendo un cuento de hadas, en donde el narrador nos aclara los puntos medulares de la historia, para que el director se encargue de llevar este cuento a un momento histórico especifico de nuestra "realidad”, únicamente para usarlo de telón de fondo y sublimar la fantasía.

Para poder regresar al reino de su padre, Ofelia necesita superar tres pruebas, en las cuales se puede interpretar que presentan rasgos semejantes a algunas problemáticas a las que se han enfrentado las mujeres a lo largo de la historia en cuestión de equidad de género ${ }^{6}$.

\footnotetext{
${ }^{6}$ Marta Lamas (1999) define el concepto de género como los procesos sociales y culturales que distinguen a lo femenino y a lo masculino, no reduciéndose a una distinción meramente biológica, en donde es elemental resaltar que las características humanas con que se relacionan a los sexos, son construcciones individuales y sociales, y no son dadas naturalmente a los individuos. Por su
} 
Cuando Ofelia es dirigida al laberinto en su primer encuentro con el fauno, después de hablarle de su pasado y plantearle las pruebas que tiene que superar, este le da a la niña una bolsa con gises y El libro de las encrucijadas, un libro en blanco, el cual le mostrará el futuro e indicará qué hacer. Quizá aquí veamos un guiño de Del Toro, quien pudiera estar enalteciendo simbólicamente la lectura y la escritura como una vía para modificar el presente y vislumbrar el futuro; la politóloga estadounidense Jane Mansbridge menciona respecto a los movimientos feministas de los 70 y la creación literaria:

Este movimiento creado en el discurso es la entidad que inspira a las actividades del movimiento y ante las que se sienten responsables (...) Hoy, las identidades feministas se crean y refuerzan cuando las feministas se unen, actúan juntas y leen lo que otras feministas han escrito (...) Leer mantiene en contacto y hace que se continúe pensando (citada en Castells, 1998, pp. 265-266).

Resulta interesante la reflexión de Daniel Chávez (2011) al señalar este recurso estilístico de Del Toro, que al enfocar El libro de las encrucijadas, más que puntualizar una proximidad entre lo fantástico y lo real, se trata de una continuidad entre estos aspectos:

Estos paneos de transición se hacen de manera horizontal casi siempre de derecha a izquierda y solo en tres ocasiones se hacen de manera vertical. En el plano horizontal representan la forma en que pasamos las páginas de un libro, y el hecho de que en un lado quede el mundo real y en el otro aparezca el fantástico o viceversa enfatizan la contigüidad entre ellos en la mente de la protagonista y para los ojos del espectador. A medida que avanza la película estas transiciones subrayan ya no la contigüidad sino la continuidad entre los dos mundos y la creciente interferencia y conexión entre los mismos hasta el punto en el que las acciones en el mundo fantástico se convierten en base causal de los hechos en el mundo real (pp. 401-402).

parte, Joan Scott (1996) señala que género es: "una forma primaria de relaciones significantes de poder” (p. 289); la autora menciona que si bien el género no es el único campo en donde se articula el poder, si señala que este es un campo primario en el que, o por medio del cual, se ha facilitado de manera persistente a lo largo de la historia la significación del poder en Occidente.
En la primera prueba, el libro le narra a Ofelia la armonía que existía en la antigüedad entre animales, hombres y criaturas fantásticas, los cuales dormían a la sombra de un frondoso árbol; sin embargo, el árbol ahora está muriendo, ya que dentro de este habita un sapo, quien no lo deja sanar. La misión de la niña es hacer tragar al anfibio tres piedras ámbar y sacar una llave de su estómago. En los cuentos de hadas clásicos, una de las figuras recurrentes es el príncipe convertido en sapo, el cual espera el beso de la amada para recuperar su figura, y vivir juntos y ser felices para siempre; sin embargo, este sapo está consumiendo el hogar y la armonía de todas las especies, el anuro no se convirtió en príncipe y envenena la vida que le rodea; si el sapo representa el patriarcado, el árbol podría representar la feminidad ${ }^{7}$.

Ofelia llega hasta el árbol vestida como una “princesa”, así lo afirma su madre, pero tiene que arrastrarse por el lodo para cumplir con su misión, es decir, dejar atrás la representación de lo que su madre y el capitán esperan de ella, quienes reproducen el discurso más tradicional en el filme.

$\mathrm{El}$ árbol que nos plasma Del Toro bien puede representar una feminidad mustia a causa de que en su interior vive un sapo del que se espera un día se convierta en príncipe. Esta transformación, clásica en los cuentos de hadas, está sumamente relacionada con el amor romántico. El sociólogo inglés Anthony Giddens (1995b), en su definición sobre los tipos de amor, nos dice que el amor romántico, marcadamente femenino, florece de la mano del afianzamiento de la novela como género literario; en este tipo de amor se individualiza

\footnotetext{
${ }^{7}$ En este sentido, Brígida M. Pastor (2011), desde un enfoque psicológico, observa una vinculación entre la monstruosidad y la noción cultural de género en este filme de Del Toro. Pastor observa los personajes masculinos definidos por el poder, el consumo, la destrucción y la inflexibilidad, mientras que en los personajes femeninos ve cualidades y características ligadas a la creatividad, la generosidad, la abnegación y a la libertad. Particularmente en la secuencia que corresponde al árbol y el sapo, la autora española señala cierta analogía entre el anfibio y Vidal, dicho de otra forma, la representación de las características que asocia a los personajes masculinos: "Vidal, sin lugar a dudas, es como el sapo-monstruo que Ofelia se encuentra en las raíces profundas del árbol marchito, que 'no le deja sanar' (...) Ambos amenazan con destruir y 'devoran’ con avidez” (p. 396).
} 
a los amantes, situándolos en una historia personalizada en donde se asocia el amor y la libertad como valores prioritarios ligados estrechamente con la autorrealización; más que la sexualidad, la idealización del otro es lo que caracteriza al amor romántico, lo que lleva a concebir a la relación de pareja como única alternativa para llegar a un estado de plenitud, es decir, se proyecta primordialmente a futuro ese bienestar ${ }^{8}$.

Cuando Ofelia consigue terminar la prueba exitosamente, consiguiendo la llave de las entrañas del sapo que le ayudará en las siguientes pruebas, sale y ve su vestido arruinado en las inmediaciones del gran árbol, atavío que había sido confeccionado por su madre para una cena especial que se llevaría a cabo en presencia de los distinguidos amigos de su padrastro [FiguRA 2]. Al regresar a su casa, en donde llevan toda la tarde buscándola, es reprendida por su madre por llegar en esas condiciones y es enviada a bañarse, castigada sin cenar. En la escena de la mesa en donde se sirve la cena, se puede observar entre otros invitados, a un sacerdote en medio de deliciosos platos, justo como la criatura monstruosa que escenificará la segunda prueba de Ofelia [Figura 3].

La segunda prueba consta de que Ofelia dibuje en la pared de su habitación una puerta con uno de los gises que le fue dado, por la cual ingresará en un pasillo que la llevará hacia un gran comedor en donde podrá elegir entre tres cajas (una de las cuales abrirá con la llave obtenida en la primera prueba). A la mesa, rodeado de manjares, se encuentra el Hombre Pálido, muy parecido al sacerdote de la escena anterior. El recinto se encuentra rodeado de retablos del estilo en que se plasma la pasión de Cristo en las iglesias, solo que en estos cuadros se observa al Hombre Pálido devorando niños. La advertencia del fauno a Ofelia, "no comáis ni bebáis nada, absolutamente nada”, nos puede remontar a ese momento en la eucaristía donde se invita a comer y beber del cuerpo y la

${ }^{8}$ Cabe mencionar que el amor romántico, en parte, ha sido analizado como un instrumento de dominación por el cual la mujer es orillada socialmente a reproducirse y relegarse a labores domésticas, lo cual suscita que la representación de la mujer tradicional continúe vigente (Federici, 2013). sangre de Jesucristo ${ }^{9}$. El Hombre Pálido es un ser enclenque que al ver su cuerpo flácido nos evidencia que anteriormente estaba entrado en carnes, quizá una insinuación al gran poder que tuvo la iglesia y que ha perdido paulatinamente. Hay que recordar que una de las posturas más marcadas del bando republicano fue su radical anticlericalismo ${ }^{10}$.

En este sentido, en entrevista con Mark Kermode, Del Toro mencionó respecto al Hombre Pálido:

\begin{abstract}
Quería representar el poder político dentro de las criaturas (...) Y ese personaje en particular vino a representar a la Iglesia y al devorador de niños. El diseño original era solo un anciano que parecía haber perdido mucho peso y estaba cubierto de piel suelta. Luego le quité la cara, por lo que se convirtió en parte de la personalidad de la institución. Pero entonces, ¿qué hacer con los ojos? Así que decidí colocar estigmas en las manos y meter los ojos en los estigmas. Habiendo hecho eso, pensé que sería genial hacer los dedos como plumas de pavo real que se ablandan y se abren. Así evolucionó esa figura (Del Toro, 5 de noviembre de 2006$)^{11}$.
\end{abstract}

Sin embargo, esta prueba no es completamente superada por Ofelia, quien después de conseguir una daga en una de las tres cajas, no ha podido resistir la tentación y toma del banquete el fruto prohibido por el fauno, acción que provoca la incorporación de su estado pasivo del Hombre Pálido, quien devora a dos de las hadas que le han sido encomendadas a la niña para ayudarla en las pruebas. A pesar de todo, Ofelia logra escapar del comedor y regresar a su habitación;

\footnotetext{
${ }^{9}$ Marianna De Tollis (2017) observa en la escena del Hombre Pálido una clara referencia al poder y a la religión en este personaje, relacionándolo con el franquismo: "Una religión ciega dispuesta a abandonar sus propias enseñanzas a cambio de poder (material y político)” (p. 48).

${ }^{10}$ La representación de la mujer dentro de la religión a lo largo de la historia es un tema sumamente enmarañado y cuenta con diferentes perspectivas, en donde muchas veces las creencias de diferente clase sirven de base para construcciones culturales, encumbrando dogmatismos que suelen crear desigualdades entre hombres y mujeres. "La religión ha ejercido una impronta poderosa en la concepción y el modelo de mujer que debe prevalecer en la sociedad; un ideal que subyace en la inferioridad y la sumisión del género femenino y en la dominación del varón” (González Pérez, 2010, p. 474).

${ }^{11}$ La traducción es mía.
} 


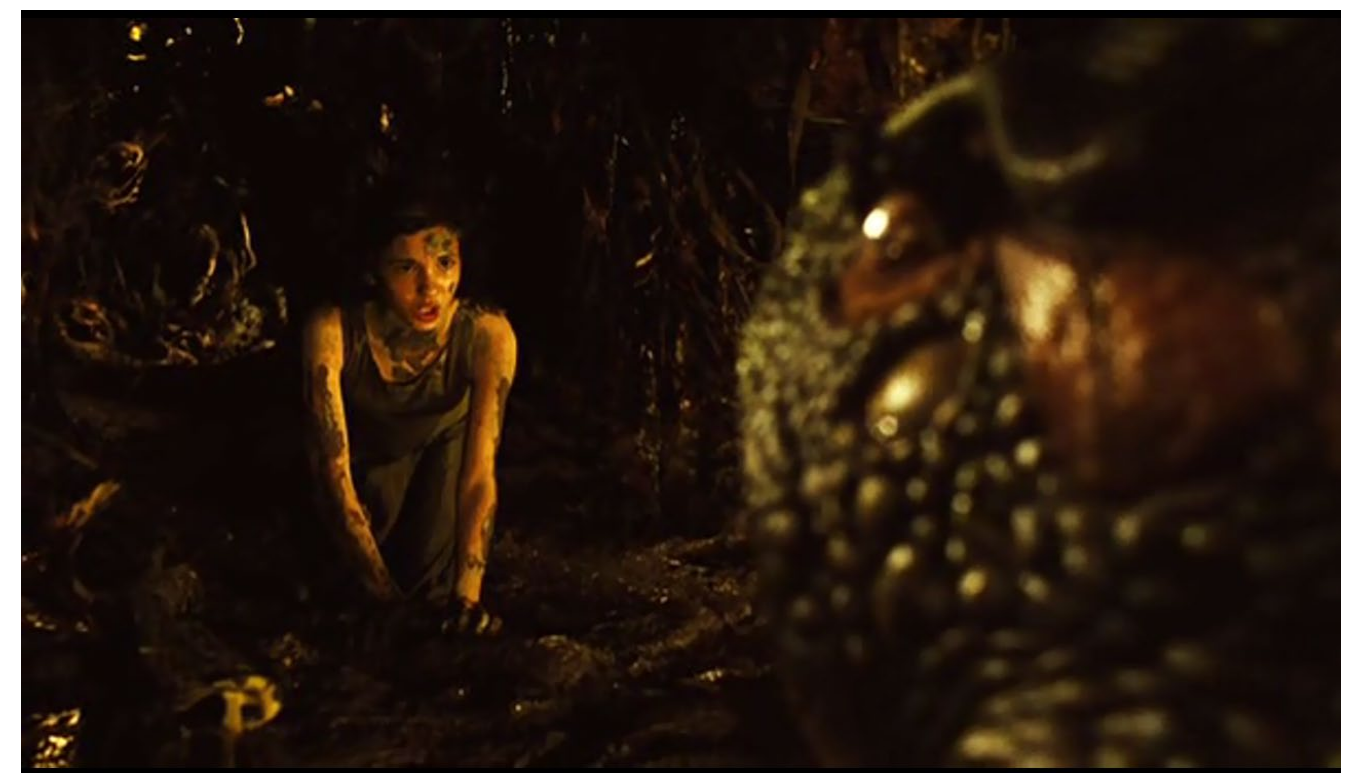

FIGURA 2. Ofelia superando la primera prueba. El laberinto del fauno

(Guillermo del Toro, 2006).

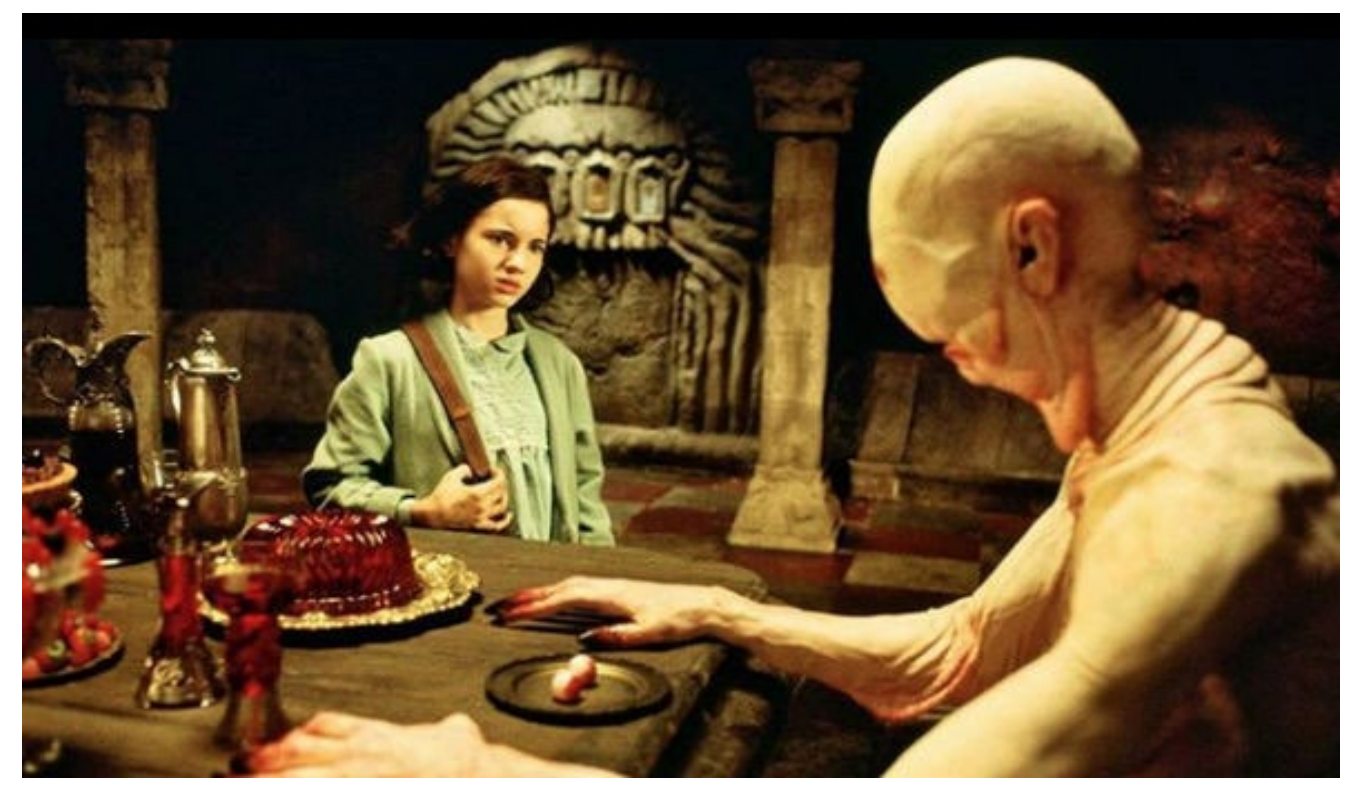

FIGURA 3. El festín del Hombre Pálido. El laberinto del fauno

(Guillermo del Toro, 2006). 
al enterarse de lo sucedido, el fauno se enfurece y veda la oportunidad a Ofelia de acceder a la tercera prueba: no habrá paraíso.

\section{El cuento de hadas con mujeres modernas}

El personaje de Ofelia representa la conexión entre la realidad y lo fantástico, es el único ser en el filme capaz de tener un contacto amplio con los dos mundos, lo cual la coloca evidentemente como un humano sensible, con facultades de rebasar las representaciones que le son dadas en primera instancia, capaz de observar nuevos mundos. Cabe mencionar que Ofelia, siendo niña, es la única que, con esa capacidad de moverse en el mundo real y en el fantástico, aprende a aceptar (y vencer) a las criaturas más diversas ${ }^{12}$.

Carmen, la madre de Ofelia, podría ser un tipo ideal de la mujer tradicional, ya que durante su embarazo se encuentra en un estado vulnerable permanentemente, obediente a su esposo, con actitud sumisa al no querer contrariar a este. Cuando Ofelia no puede iniciar la segunda prueba y es cuestionada por el fauno acerca de las causas, comenta que es por su madre, ya que su estado delicado le impide apartarse de ella. Entonces el fauno le da una mandrágora y le da indicaciones de cómo prepararla y posicionarla para que mejore la salud de su madre. El brebaje es descubierto por el capitán Vidal debajo de la cama de su esposa, regaña a Ofelia y la deja con su madre para que la reprenda. En la acalorada charla que sostienen, Carmen echa al fuego la planta, diciendo a Ofelia: "El mundo es un lugar cruel, y eso vas a aprenderlo". Acto seguido Carmen se desvanece y muere dando a luz. El fatalismo de una vida infeliz y subordinada, el negarse una utopía, como la que construye Mercedes, o como la que

\footnotetext{
${ }^{12}$ Deborah Shaw considera que este filme de Del Toro se puede interpretar como una obra feminista. Respecto a este personaje, la autora menciona: "En Ofelia, Del Toro crea una heroína luchadora, valiente, desobediente, rebelde, imaginativa y de buen corazón para contrarrestar el arquetipo femenino pasivo en el cuento de hadas tradicional" (citada en Vargas, 2016, p. 164). La traducción es mía.
}

imagina Ofelia, hace que Carmen no sea propensa a un cambio, y al renunciar a la felicidad, perece.

Por otro lado, el capitán Vidal representa el poder patriarcal del fascismo. Tiene una posición de respeto en el ejército, y tiene una actitud impasible ante los que considera inferiores a él. Como figura paterna prefiere tener un varón que una mujer como hija, y tiene un notorio desagrado por Ofelia. Del Toro se esfuerza en dejarnos claro el orden inalterable al que trata de mantenerse sujeto el capitán, es decir, al no cambio, desde su constante revisión del tiempo en el reloj que su padre le dejó al morir en batalla, hasta en los grandes engranajes que hay en su oficina. Vidal no escucha a nadie y esto lo lleva a un fatídico final. El recalcitrante personaje engloba la necedad y cerrazón de las instituciones que representa, las cuales llevan como bandera la "verdad y la libertad".

Mercedes podría representar a la mujer moderna; la actividad de este personaje no se limita a ser una ama de llaves, ya que es en realidad una infiltrada de la resistencia rebelde y no duda nunca de sus ideales, a pesar de tener que mostrar una actitud sumisa frente al capitán. Mercedes aborrece su representación ante Vidal, pero solo la mantiene por la utilidad que tiene para destruirlo a él y todo lo que representa ${ }^{13}$ [FIGURA 4].

El doctor Ferreiro, hombre rebelde, es sensible a la situación de los otros, quien reconoce la virtud de Mercedes, su compañera de batalla. El doctor es quien, al no poder llevar más adelante su personaje sumiso frente a Vidal, decide darle una muerte rápida al tartamudo capturado en las montañas y torturado en la aldea; él dice a Vidal cuando este le recrimina el no seguir su orden de incorporar al preso para continuar con el interrogatorio: "Obedecer por obedecer, así, sin pensarlo, eso solo lo hace gente como usted, capitán”.

\footnotetext{
${ }^{13}$ Para Brígida Pastor (2017), Mercedes al final del filme restituye su integridad femenina, cuando dispara al capitán Vidal, quien durante todo el filme menosprecia al género femenino. Haciendo alusión a los asesinatos del doctor y del tartamudo capturado en las montañas por parte de Vidal, Mercedes exclama: "Yo no soy un viejo. Tampoco un prisionero herido", y dispara.
} 
La prueba final:

el amor fraternal

Cuando se abre el combate frontal entre franquistas y rojos, el fauno concede una última oportunidad a Ofelia de realizar la tercera prueba y así regresar a su reino. La niña, con su hermano en brazos, huye entre disparos a las entrañas del laberinto, siendo perseguida por Vidal. La última prueba, dice el fauno, consiste en que Ofelia provoque un corte en el cuerpo de su hermano con la daga que encontró en el comedor del Hombre Pálido, para que con su sangre se abra un portal en el laberinto que la llevará al reencuentro con su padre. Ofelia se niega rotundamente a seguir la insistente indicación del fauno, aun cuando este la intenta sugestionar mencionándole las grandezas que perderá por defender a un ser al que apenas conoce. Si bien atrás he hecho mención del amor romántico, el cual se vincula particularmente con las relaciones de pareja, se puede decir sin duda que el amor en general no se limita a esto y lo supera por mucho. Para Erich Fromm (1959), el amor fraterno es la base de todos los tipos de amor:
"La clase más fundamental de amor, básica en todos los tipos de amor, es el amor fraternal. Por él se entiende el sentido de responsabilidad, cuidado, respeto y conocimiento con respecto a cualquier otro ser humano, el deseo de promover su vida” (p. 52).

Es así como el amor de Ofelia cumple con todas estas características: es un amor sin exclusividad. Pese a saber que le espera su verdadero padre, Ofelia renuncia al reino que se le ofrece. "El amor solo comienza a desarrollarse cuando amamos a quienes no necesitamos para nuestros fines personales" (p. 54). Esta decisión provoca que el fauno se despida y la deje sola en el laberinto en donde es alcanzada en breve por su padrastro, quien dispara a quemarropa a su hijastra, y recupera a su deseado hijo. La sangre que escurre por la mano de Ofelia llega gota a gota al fondo orbicular del laberinto: la prueba verdadera era demostrar su propensión al amor fraternal. Ofelia pone por encima el cuidar la sangre inocente antes que su interés de ser princesa. Esta acción abre el portal en donde la espera una comitiva de bienvenida encabezada por el fauno; su padre le comenta que ha superado la última
FIGURA 4. Mercedes y Ofelia. El laberinto del fauno (Guillermo del Toro, 2006).

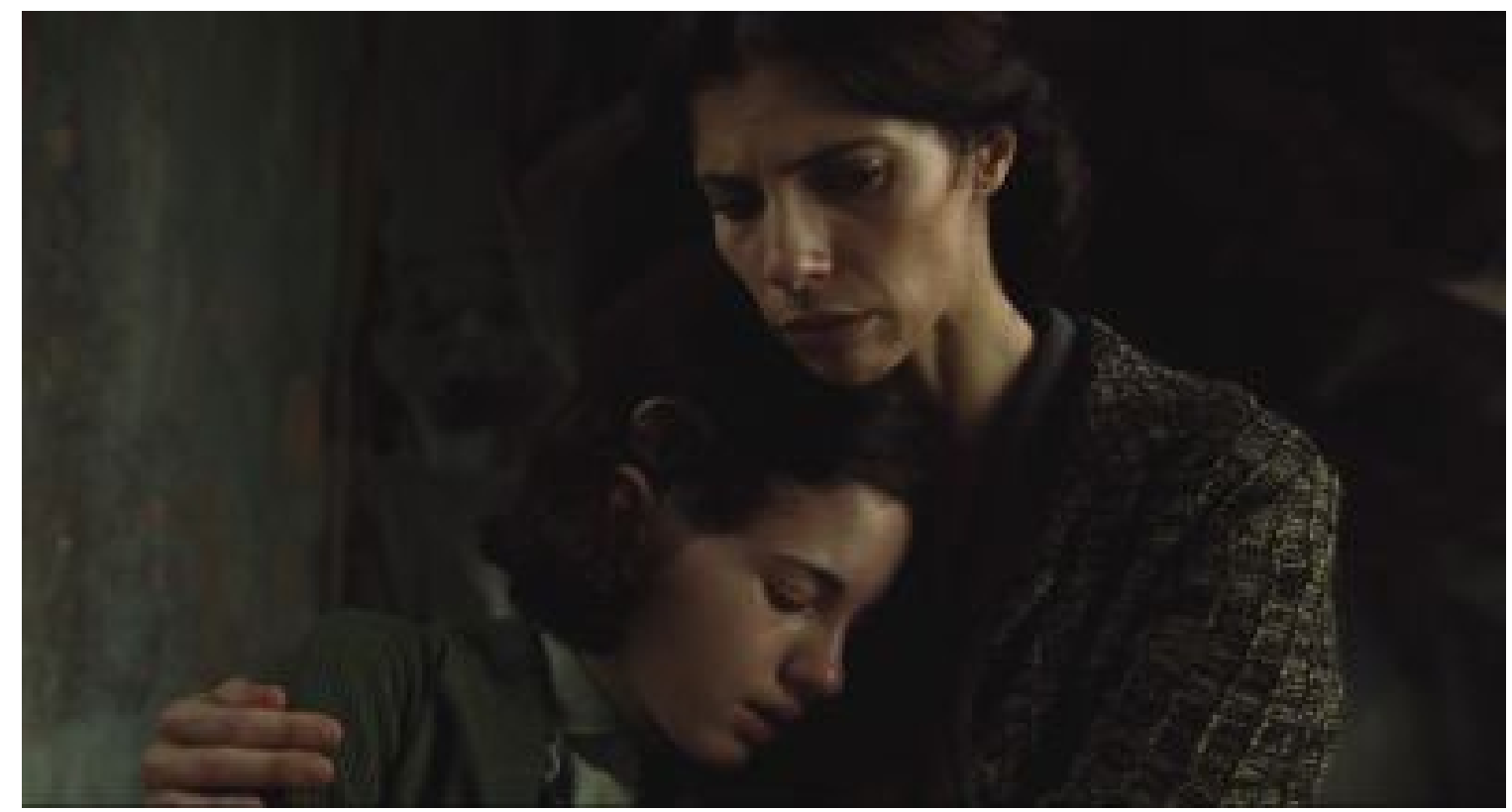


prueba, y ahora está seguro de que su hija no ha cambiado su esencia en el largo tiempo de ausencia, o dicho de otro modo, no se ha convertido en humana. Del Toro lleva hasta el final el discurso de poner siempre en segundo plano a lo real, siempre asegurando la fantasía como único escape de una realidad humana demasiado paradójica. Siempre triunfa la utopía con Del Toro.

\section{LA FORMA DEL AGUA}

La forma del agua se desarrolla principalmente en una base militar de investigación en los Estados Unidos en plena Guerra Fría, en donde la moza del laboratorio, Elisa Esposito, se enamora de un anfibio humanoide capturado en el Amazonas. Ella, por un lado, es una mujer muda en un ambiente estructurado patriarcalmente. Él, por el otro, es un anfibio humanoide mantenido con vida mientras se toma la decisión de cuándo será sacrificado para diseccionar su cuerpo en busca de obtener información útil al ejército norteamericano para ganar la carrera espacial a los rusos. El coronel Strickland es quien comanda esta misión, y al igual que el capitán Vidal, desde el inicio del filme deja clara su figura autoritaria.

Del Toro hace una oda a la otredad, en donde con base en la fantasía impregna su obra de tintes políticos, siempre en búsqueda de reivindicar de manera luminosa a lo diferente. Esta parábola retrata su lado más personal, ya que como él mismo ha señalado: "Soy mexicano, he sido la otredad toda mi vida" (citado en \#0 Cerotube, 10 de octubre de 2017, 04:35). No es nuevo saber que este director se proyecta en los monstruos que protagonizan sus películas. No solo eso, la parte más humana de sus filmes la manifiestan estos, y la parte más monstruosa la expresan los humanos, particularmente los personajes que encabezan a las diferentes instituciones que se engloban en sus filmes, los más empoderados.

La forma del agua se desarrolla en los años 60, en medio de todas las grandes revoluciones contraculturales juveniles, sexuales, raciales, entre otras, que aún reverberan en el centro de preocupaciones contemporáneas a sesenta años de iniciadas. Aún existe una marcada inequidad de género, la diversidad sexual sigue siendo sumamente cuestionada, los jóvenes siguen siendo discriminados, y el racismo ha resurgido de la mano de los políticos.

Por lo anterior, me parece sumamente interesante que Guillermo del Toro haya entrado en su ambiciosa trama por la puerta de servicio, es decir, elige a una moza que no tiene voz, amiga de una afroamericana y un homosexual, y que trabaja en un laboratorio militar patriarcalmente jerarquizado. Hubiera sido sumamente sencillo y predecible que un personaje empoderado, entrando por la puerta principal de la base militar, se compadezca de una criatura monstruosa, la domestique y la "normalice" (si es que esto existe en algún modo), pero de eso hablaré más adelante. Sin embargo, Del Toro sabe del poder desorganizador del amor, le pone a este el rostro de una criatura difícil de descifrar, la cual es un espejo en el que cada quien puede reflexionar su manera de vincularse con lo diferente, en donde algunos personajes terminan por observar que son más monstruosos que la misma bestia.

$$
\begin{array}{r}
\text { El amor de Elisa } \\
\text { y el monstruo }
\end{array}
$$

Si bien anteriormente he hablado del amor romántico y del amor fraterno, en esta cinta quiero destacar el amor confluente, el cual considero es el que más se destaca entre Elisa y el monstruo, al que Giddens (1995b) distingue como el amor en donde las personas mantienen vínculos en función de sí mismas y no por lo que obtienen de su pareja; esta relación solo es mantenida en medida en que cada individuo encuentra satisfacciones en la relación. A diferencia del amor romántico, el amor confluente no idealiza a una persona, sino que reconoce los valores de esta; el saber que una relación puede o no tener límite de tiempo es algo intrínseco a este tipo de amor.

Hago alusión al concepto de amor confluente de Giddens, en contraste con el de amor romántico, para evidenciar 
la visión y profundidad con la que Guillermo del Toro enlaza su trama, ya que por tener una estructura parecida a la de los cuentos de hadas, podríamos homologarla con las princesas hollywoodenses que están en cartelera todos los fines de semana.

Esta película, al igual que El laberinto del fauno, inicia y termina con una voz en off, en la que el narrador da una sensación de circularidad a la historia. El narrador nos indica desde el inicio, aunque solo los más perspicaces se dan cuenta de esta revelación en primera instancia, cuando habla de "la princesa sin voz" y "el monstruo que una vez quiso destruirlo todo", que la monstruosidad se entenderá desde la sensibilidad y el razonamiento descompuesto. Esto da todo el sentido a la película: a través de la proyección que tiene el coronel Richard Strickland con el anfibio, exhibe la parte más monstruosa del ser humano, el cual evidencia la doble moral existente en las instituciones y en los valores que encarniza este personaje [FIGURA 5]. A la vez, este es un reflejo del discurso de esa parte de la sociedad contemporánea que no logra aceptar a la otredad, esa sociedad que empuja a Del Toro a realizar esta parábola. En este sentido, Fernanda Solórzano (2017) considera que este aspecto es lo que convierte a este filme en la más adulta y subversiva del director, particularmente por:

La forma en que Del Toro remonta contra la doble moral de ciertas instituciones y de los valores que promueven -la misma doble moral que causa estragos en el presente, y que contribuye a la reaparición de fascismos que se creían extintos (pp. 70-71).

Solórzano considera que los seres fantásticos que aparecen en las películas de Del Toro no son sinónimos de maldad, y quienes en la trama señalan la monstruosidad en estos, tan solo evidencian su miedo a lo diferente. Precisamente, esta crítica ve que a través del personaje de Strickland, se representa el discurso radical de la derecha religiosa, la exaltación del modelo de familia tradicional, además de vincular el acoso sexual con el abuso de poder, y que, si bien este personaje captura los valores predominantes en la posguerra estadounidense, también echa luz sobre lo poco que ha cambiado con ciertas personalidades contemporáneas, entre los que Solórzano menciona a Harvey Weinstein o Donald Trump.

Elisa Esposito no solo es una mujer muda y soltera que trabaja en la limpieza en un ambiente poco incluyente, sino que es plena, lleva una vida feliz, satisfecha sexualmente y Del Toro nos lo deja claro en los primeros cinco minutos del filme cuando ella se masturba por la mañana. Estamos acostumbrados culturalmente a las historias en donde implícitamente se nos dice que estamos solos y que necesitamos estar acompañados de una pareja para ser plenos y realizados. Pienso que esto distingue a La forma del agua de las otras historias con la que se comparó y acusó de plagiarlas. Si bien siempre ha habido historias entre bellas y bestias, es decir, entre otredades, aquí la primicia es que la plenitud es alcanzable en solitario, lo que hace asequible entablar una relación de amor confluente para estos dos personajes.

$$
\begin{aligned}
& \text { No idealizar y conocer al otro: } \\
& \text { comerse al gato antes del amor }
\end{aligned}
$$

Una de las secuencias clave en la película que sirve para sostener mi hipótesis es cuando el anfibio, después de que Elisa logra sacarlo del laboratorio, se come al gato de Giles, su vecino, situación que perturba a los dos humanos. Simbólicamente es muy relevante que antes de cualquier enamoramiento, antes del primer encuentro sexual, el ser amado demuestre su naturaleza, sus instintos, sus defectos, dejando así a la otra parte la decisión de si desea o no aceptar al otro; en otras palabras, en esta escena se deja claro que antes de dar un paso al amor, las dos partes conocen lo bueno y lo malo del otro. Este elemento es uno más que hace que La forma del agua sea un filme que no se pueda homologar tan simplemente a otras cintas comerciales.

Giddens menciona que si no hay un conocimiento general de la pareja no se podrá tener igualdad en la relación. "El amor confluente, aunque no necesariamente andrógino, 
FIGURA 5. Strickland, Elisa y Zelda. La forma del agua (Guillermo del Toro, 2017).

FIGURA 6. Strickland leyendo. libros de autoayuda La forma del agua (Guillermo del Toro, 2017).
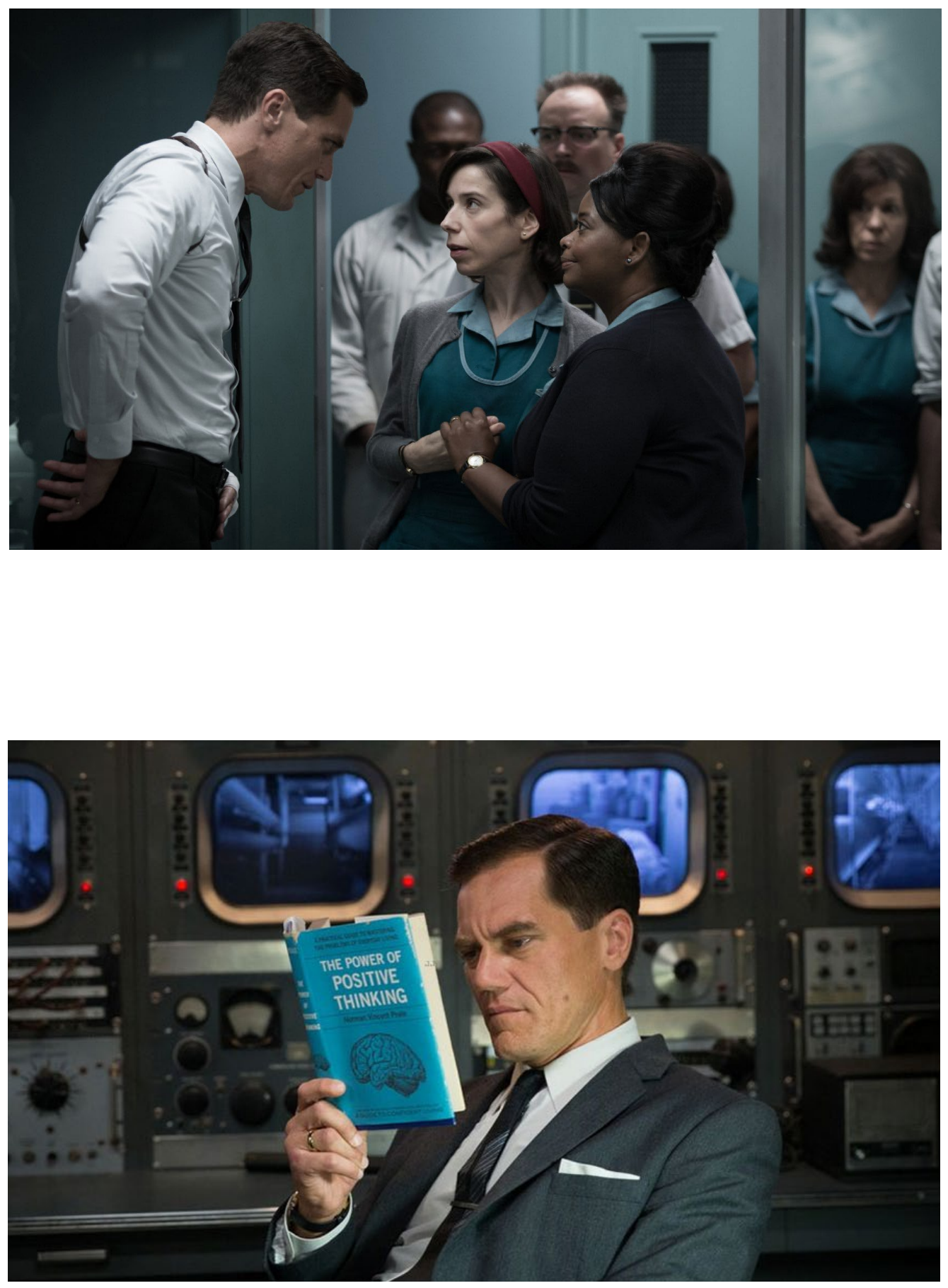
y quizás todavía estructurado alrededor de la diferencia, presupone un modelo de relación pura, por la razón de que un hecho básico del mismo es conocer los rasgos del otro" (1995b, p. 40).

La forma del agua en primera instancia nos podría remontar a La Bella y la Bestia, el relato de Beaumont que ha sido la versión en que se basa la mayoría de adaptaciones posteriores de este cuento francés, en donde el engendro termina convirtiéndose en un príncipe; pero la no transformación de la bestia en un caballero atractivo es donde principalmente marca sus diferencias el filme de Del Toro, en comparación a todos los cuentos en donde el amor termina por cambiar al ser amado, un amor romántico esencialmente ${ }^{14}$.

Para que se pueda dar el amor confluente debe existir un marco ético para propiciar emociones no destructivas en la conducta individual y comunitaria (p. 122). La emoción como tal es una forma de comunicarse; en el amor confluente no hay espacio para las hegemonías. Cuando Elisa pide ayuda a su vecino Giles para llevar a cabo su plan de liberar al anfibio en la costa de la ciudad, él se niega y discuten. En su lengua de señas, de manera muy emotiva, ella señala que el anfibio es igual a ella, menciona que él mueve la boca como ella, pero no emite sonidos (un símbolo de que su voz en su contexto social no es escuchada). Elisa crea un vínculo con el otro a través de su misma condición, equiparando sus emociones, y esto es lo que propicia una comunicación eficiente entre los amantes, aun cuando no comparten símbolos en común para comunicarse. Al final, Giles acepta ayudarla.

\footnotetext{
${ }^{14}$ En La forma del agua esta característica es la que le da mayor distinción ante la gran ola de denuncias por supuestos plagios a otros libretos o películas, por ejemplo: Let Me Hear you Whisper (Paul Zindel, 1969) o The Space Between Us (Marc S. Nollkaemper, 2015), por mencionar algunas. Estas historias señaladas fueron causa de polémica, ya que se adjudicaban la originalidad de la historia de amor entre una criatura marina y una mujer; existieron demandas hacía Del Toro, sin embargo, estas no prosperaron al no contar con suficientes elementos para constatar el supuesto plagio.
}

\section{EL AMOR ESTÁ COMPUESTO POR VARIOS TIPOS DE AMORES}

Como se ha observado a lo largo del texto he utilizado diferentes conceptos que se desprenden directamente de la emoción del amor, sin embargo, es importante recordar que estos tipos de amor son utilizados como tipos ideales, es decir, no se dan de manera pura en la realidad, pueden estar entremezclados. Para finalizar, a continuación me propongo argumentar el por qué considero que, en esta cinta, de los tipos de amor que podemos identificar en ella, el amor confluente es el que más destaca sobre todos.

Elisa nunca está sola, si uno observa cuidadosamente la película se podrá notar que siempre está acompañada. Ella tiene a su vecino Giles, tiene a su compañera de trabajo Zelda, encuentra empatía en Dimitri, el infiltrado ruso en el laboratorio, y las breves ocasiones en que se encuentra sola reboza plenitud. Si uno observa a los demás personajes, es notable cómo a partir de Elisa, todos en descendente están cada vez más solos. Giles con su amor no correspondido por un joven barman homofóbico, Zelda con su nefasto esposo, Dimitri en una encrucijada colateral, así hasta llegar a Richard Strickland, el personaje más solitario en toda la película. Strickland es quien lee manuales de autoayuda (El poder del pensamiento positivo), se autodenomina un hombre decente, detesta que su esposa se quiera comunicar con él. El verdadero monstruo de la película usa traje y corbata y maneja un Cadillac; es el tipo ideal de un hombre exitoso para gran parte de la sociedad de su época [Figura 6].

El filme está situado a mediados del siglo XX. En ese momento en los Estados Unidos se estaban viviendo las consecuencias que el estado de bienestar había cultivado, entre otras cosas, a una generación de jóvenes con la oportunidad de disponer de gran tiempo libre para el ocio y con cierta solvencia económica para consumir los productos culturales de 

productos culturales masivos que evidencien esta sumisión. Si Strickland representa a las instituciones y los valores generales de la época, resulta evidente que Elisa y el anfibio son la antítesis, es la búsqueda de liberarse de esa institucionalización del yo; Del Toro, con el recurso de la fantasía encuentra la manera de dar un escape hacia un amor confluente [FIGURA 7].

Si bien es cierto que a lo largo de la película podemos observar elementos de amor romántico, sabemos que sociológicamente, como se mencionaba al inicio del apartado, tan solo son tipos ideales, es decir, el fin no es encontrarlos de manera pura en la realidad, sino observar sus contrastes y de ahí sacar conclusiones. Es inminente que el final de la película, cuando los dos amantes están en el agua, parece tener un dejo de amor romántico, ya que Elisa y el anfibio parecen estar predestinados a estar juntos. La fuerza del destino actúa, tal como nos lo describe Giddens. Tomemos en cuenta de que se trata de una película de género fantástico y que el final no podía ser de otra manera: Elisa es de la misma especie que su amante y ya en el agua, las tres cicatrices en su cuello se convierten en branquias [FIGURA 8].

Aun con lo anterior, si vemos a fondo el símbolo que Del Toro impregna a esta escena, el amor confluente es el concepto al que más se asemeja cuando realizamos el ejercicio de clasificar el tipo de amor que observamos en pantalla. En realidad, no se trata de la fuerza del destino, las cicatrices no indican la predestinación, sino que esas heridas que impregnaron una marca en su ser dejaron un aprendizaje, el cual permite una liberación que le deja respirar, pero no entendiendo esa liberación como escape, sino como asimilación: el amor confluente no es descubrimiento, es reconocimiento. La capacidad de Elisa de autoconocerse y reconocer al otro viene de sus cicatrices. Así, cuando en la última escena a ella se le desprende la zapatilla roja de su pie, podría simbolizar la liberación de todos los prejuicios dañinos de su pasado; a final de cuentas, el amor confluente es contingente, nos puede embarcar en un enamoramiento para toda la vida, o no. El final feliz es una probabilidad.

\section{Conclusión}

A decir verdad, se pueden encontrar grandes paralelos en estas dos historias. Personalmente considero que El laberinto del fauno es una trama más complicada y con símbolos más sustanciosos a la hora de realizar un análisis; sin embargo, observo que La forma del agua es una película mejor lograda, o al menos es más eficiente en comunicar su mensaje al espectador. Guillermo del Toro la considera como su trabajo favorito, aceptando que: "Tenía claro que quería una película que estuviera enamorada del cine, y no de un cine cualquiera, sino del cine dominguero, de entretenimiento, que muchas veces es el que te salva la vida" (citado en Guirado, 9 de diciembre de 2017).

En La forma del agua el amor en pareja triunfa, pero los protagonistas son autosuficientes individualmente, son plenos desde antes de conocerse, ella con su vida de soltera y él siendo venerado como un dios en el Amazonas, y cuando están juntos tan solo quieren ratificar su cosmovisión en pareja, no como escapismo sino como reafirmación. En El laberinto del fauno se rechaza por completo la realidad, lo onírico es la única salida; Ofelia es un ser incompleto que necesita el reconocimiento del otro, irónicamente la figura paterna, para llegar a la plenitud.

A pesar de tener una estructura similar a la de los cuentos de hadas, podemos observar que ambos filmes, que rápidamente se ubicaron como fenómenos de masa, manejan un discurso que trata de plasmar una transición de la representación tradicional de la mujer hacia una moderna. Si como mencioné anteriormente, en otros filmes igualmente apegados a la tradición cinematográfica estadounidense es contradictoria la representación moderna de la mujer que se intenta dar, pienso que la obra de Del Toro logra superar, sobre todo en La forma del agua, esta constante.

Tanto Ofelia, Mercedes y Elisa figuran como mujeres no apegadas a una representación tradicional, que en el caso de 
estas películas, Del Toro encuentra los contrapesos comparativos principalmente en los personajes de Zelda y Carmen. A lo largo de este escrito he ido vinculando a las herónas de estos dos filmes con el amor, definido desde diferentes tipificaciones, dentro de las cuales se fue señalando su desapego a la concepción tradicional de la mujer (la cual es relegada como un ser pasivo ante lo masculino), presentándose a una heroína con iniciativa y siendo un ente activo en la toma de decisiones dentro de la trama. Si bien Ofelia se vinculó con un tipo de amor comunitario y a Elisa con uno más apegado a lo que respecta a las relaciones de pareja, sin duda en ambos casos esta emoción ha sido el revulsivo por el cual la figura femenina se sobrepone a las adversidades de su entorno.
Este tipo de productos culturales pueden llevar a que nuevas generaciones asimilen los roles de género y su vinculación por medio del amor de otras formas, y así modificar ciertas relaciones sociales, en donde la equidad sería un buen parámetro para medir qué tanto la inserción de productos culturales masivos en el imaginario colectivo modifica esas relaciones sociales. Para este último punto, solo queda seguir investigando, ahí donde se dan los cambios, para saber precisamente qué expresiones culturales tienen mayor influencia en los espectadores. 


\section{Bibliografía}

Castells, M. (1998). La era de la información Vol. 2. El poder de la identidad. Madrid, España: Alianza.

Chávez, D. (2011). De faunos hispánicos y monstruos en inglés, la imaginación orgánica en el cine de Guillermo Del Toro. En J. C. Vargas (Coord.), Tendencias del cine iberoamericano en el nuevo milenio: Argentina, Brasil, España y México (pp. 371-407). Guadalajara, México: Universidad de Guadalajara.

DE Tollis, M. (2017). El laberinto del fauno: fantasía y cristología en el personaje de Ofelia. Teatro: Revista de estudios culturales, (31), 42-57. Recuperado de https://digitalcommons.conncoll.edu/teatro/vol31/iss31/4

Echeverría, B. (2009). ¿Qué es la modernidad? Ciudad de México, México: UNAM.

GaGo, V. (abril de 2015). Entrevista a Silvia Federici. Lobo Suelto. Recuperado de http://anarquiacoronada.blogspot.com/2015/04/entrevista-silvia-federici_64.html

Gamba, S. (2008). Feminismo: historia y corrientes. En S. Gamba (Coord.), Diccionario de estudios de género y feminismos (pp. 1-8). Buenos Aires, Argentina: Biblos.

Giddens, A. (1995a). Modernidad e identidad del yo. El yo y la sociedad en la época contemporánea. Barcelona, España: Península.

Giddens, A. (1995b). La transformación de la intimidad. Sexualidad, amor y erotismo en las sociedades modernas. Madrid, España: Cátedra.

Giménez, G. (2005). La cultura como identidad y la identidad como cultura. Conferencia presentada en el Tercer Encuentro de Promotores y Gestores Culturales, Guadalajara, México. Recuperado de http://perio.unlp.edu.ar/teorias2/textos/ articulos/gimenez.pdf

González Pérez, T. (2010). Desigualdad, mujeres y religión. Sesgos de género en las representaciones culturales religiosas. Cuestiones de género: de la igualdad y la diferencia, (5), 467-505. doi: http://dx.doi.org/10.18002/cg.v0i5.3797

Guirado, A. M. (9 de diciembre de 2017). Guillermo del Toro: 'La forma del agua es mi película más humana y emotiva'. La vanguardia. Recuperado de http://www.lavanguardia.com/vida/20171209/433525672881/guillermo-del-toro-laforma-del-agua-es-mi-pelicula-mas-humana-y-emotiva.html

Federici, S. (2013). Revolución en punto cero. Trabajo doméstico, reproducción y lucha feministas. Madrid, España: Traficante de sueños.

Fromm, E. (1959). El arte de amar. Barcelona, España: Paidós.

Illouz, E. (2012). Por qué duele el amor. Una explicación sociológica. Buenos Aires, Argentina: Katz. 
JAQUETTE, J. S. (1996). Los movimientos de mujeres y las transiciones democráticas en América Latina. En S. Picado (Comp.), Estudios básicos de derechos humanos (pp. 319-350). San José, Costa Rica: Instituto Interamericano de Derechos Humanos.

Kermode, M. (5 de noviembre de 2006). 'Pain should not be sought - but it should never be avoided'. The Guardian. Recuperado de https://www.theguardian.com/film/2006/nov/05/features.review1

Lamas, M. (1999). Usos, dificultades y posibilidades de la categoría género. Papeles de población, (21), 147-178.

Pastor, B. M. (2017). La Bella y la Bestia en el cine laberíntico de Guillermo del Toro: El espinazo del diablo (2001) y El laberinto del fauno (2006). ARBOR Ciencia, pensamiento y cultura, (748), 391-400. doi: https://doi.org/10.3989/ arbor.2011.748n2017

Rodríguez Morales, Z. (2016). 50 sombras de Grey como metáfora de los dilemas afectivos y sexuales contemporáneos. En T. Rodríguez Salazar (Coord.), Representaciones mediáticas del amor, el sexo y el poder femenino (pp. 159-190). Guadalajara, México: Universidad de Guadalajara.

Rodríguzz Salazar, T. y Pérez Sánchez, I. (2014). La sexualidad femenina en el discurso de la prensa popular y la ficción televisiva. Comunicación y sociedad, (21), 15-41. doi: https://doi.org/10.32870/cys.v0i21.570

Rodríguez Salazar, T. y Rodríguez Morales, Z. (2016). Ideales y anti-ideales de sexualidad femenina en escenas de consejería sexual en una serie de ficción televisiva. En T. Rodríguez Salazar (Coord.), Representaciones mediáticas del amor, el sexo y el poder femenino. Seis estudios de caso (pp. 19-52). Guadalajara, México: Universidad de Guadalajara.

Scotт, J. W. (1996). El género: una categoría útil para el análisis histórico. En M.

Lamas (Comp.), El género: la construcción cultural de la diferencia sexual (pp. 265302). Ciudad de México, México: UnAM.

SolóRZano, F. (2017). De monstruos a monstruos. Letras libres, (228), 70-71. Recuperado de http://www.letraslibres.com/mexico/revista/monstruos-monstruos

VARGAS, J. C. (2016). La mirada infantil y los cuentos de hadas en la trilogía hispánica de Guillermo Del Toro. Entre lo real y lo fantástico. En M. Satarain (Comp.), Fundido encadenado. Reflexiones, ficciones, documental, bandas sonoras (pp. 141-170). Buenos Aires, Argentina: Universidad de Buenos Aires. 


\section{Filmografía}

\#0 Cerotube. (10 de octubre de 2017). Guillermo del toro: Soy mexicano, he sido la otredad toda mi vida [Archivo de video]. Recuperado de https://www.youtube.com/ watch? $\mathrm{v}=\mathrm{XQfyk} 0 \mathrm{CjJ} 5 \mathrm{Y}$

Del Toro, G. (Director \& Productor) \& Augustin, A., Cuarón, A., Navarro, B. y Torresblanco, F. (Productores). (2006). El laberinto del fauno. España, México: Estudios Picasso, Esperanto Filmoj, Tequila Gang, Telecinco, OMM, Sententia Entertainment.

Del Toro, G. (Director \& Productor) \& Dale, J. M. (Productor). (2017). La forma del agua [The Shape of Water]. Estados Unidos: Bull Productions, Fox Searchlight.

Salvador Iván Lupercio Madero (México) es pasante en la licenciatura de Sociología por la Universidad de Guadalajara. Actualmente finaliza su trabajo de tesis, en donde realiza un análisis sobre cómo se representa el amor en las relaciones de pareja en el filme Nuestro tiempo (2018), del director Carlos Reygadas. 